\title{
Mathematical model for optimizing the fleet of vehicles for performing land reclamation works
}

\author{
Talgat Gabdullin ${ }^{10000-0001-8232-4225]}$ and Marat Makhmutov ${ }^{1 *[0000-0002-1082-1297]}$ \\ ${ }^{1}$ Kazan State University of Architecture and Engineering, 420043, Zelenaya st., Kazan, Russia
}

\begin{abstract}
When choosing technical means for performing various technological processes and, in particular, for carrying out reclamation and cultural-technical works, two aspects should be taken into account: the fundamental possibility of using machines and the level of their reliability. But if the choice of technical means according to the fundamental possibility of use for performing a specific operation is sufficiently developed («Systems of machines», catalogs of special equipment have been developed), then the choice of means of repair and technical impact, depending on quantitative data and qualitative characteristics of reliability, is currently not fully studied. This is due to the lack of a sufficient database on malfunctions of the specified technical means and, as a consequence, the lack of reliable indicators of their reliability. Analysis of the data on the operation of technical means in land reclamation and construction organizations shows that due to the low reliability of machines, up to $40 \%$ of the cost of their work is the cost of maintenance and repair, while the share of time resources for downtime for technical reasons in the total fund of the working time reaches $40-50 \%$. It should be noted that this is only part of the damage caused by the lack of reliability of the machines. Improving the methods of using machines led to the creation of mechanized complexes - a group form of machine work. Therefore, due to the widespread use of complex mechanization in land reclamation construction, the stop of one machine of a technological complex leads to a stop of the entire technological process. Thus, the determination of the reliability characteristics of the units of technological complexes, namely, the establishment of the physical nature, failures, the identification of the causes of their occurrence, as well as the determination of the need for repair and technical actions, will provide the necessary operational and economic performance indicators of the entire technological complex in specific operating conditions. In this regard, the issue of determining the optimal provision of repair and technical impacts on the units of technological complexes, taking into account their components, is an urgent task that requires separate research.
\end{abstract}

Keywords: planning, primary tillage, irrigation, a wide variety of designs, working bodies, technological processes, mechanical engineering.

\section{Introduction}

\footnotetext{
*Corresponding author: maratmax@yandex.ru
} 
Currently, the Russian Federation has 9.1 million hectares of reclaimed land, including 4.3 million hectares of irrigated and 4.8 million hectares of drained land, with a total book value of systems of all forms of ownership of more than 340 billion rubles. Of these, a significant part of the reclaimed land (over 3.5 million hectares) is in poor condition.

The Federal Target Program «Development of agricultural land reclamation in Russia for 2014-2020» (approved by the Government decree of the Russian Federation No. 922 of October 12, 2013) provides for the commissioning of 840.96 thousand hectares of reclaimed land through reconstruction, technical re-equipment and construction of new reclamation systems, including general and individual reclamation systems; protection of 500 thousand hectares of land from water erosion, flooding and flooding through flood prevention measures; maintaining existing and creating 92.89 thousand new high-tech jobs for agricultural land, etc.

Reclamation works are carried out by both fairly large organizations and small enterprises with different technical equipment. The structure of the fleet, the technical level of machines for reclamation works and the scope of their use determine the material base and technology of reclamation production. When forming a fleet of cars and building a system of their technical service, new approaches are needed, taking into account the trends of innovative development of economic sectors in Russia and abroad. The need for such a statement of the problem is connected with the fundamental changes that have developed in the market of machines for reclamation works: the technologies of work performance and the structure of the fleet have changed, the equipment of foreign companies has appeared, there has been a sharp decline in the production of domestic machines.

The basics of modeling and making optimal decisions in the formation of a fleet of cars are considered in the works of A. I. Buryanov, L. I. Golovashkin, A. N. Didmanidzea, V. D. Ignatov, V. A. Makuev, R. M. Mikhailov, A.V. Peskarev and a number of other researchers. However, the developed and applied methods allow you to complete the fleet of machines under the specific conditions of the operating organizations, without taking into account the reliability indicators of the machines in question. As an optimization criterion, many scientists, as a rule, take the minimum of the reduced costs, without taking into account the costs of unplanned machine downtime. Analysis of research on this problem in recent years shows that it is insufficiently studied.

Basically, the work is devoted to the study of methods for the formation of development schemes, the functioning and state of the production and technical base. These are such works as A. F. Zakuraeva. "Improvement of the forms of development of the production and technical base of enterprises of motor transport management» [1], I. P. Kurnikov. «The main directions of development and effective use of the production and technical base of road transport» [2], Umarova E. R. «Modeling the development of the production and technical base of road transport» [3], Kamoltseva A. V. «The system for assessing the state of the production and technical base of motor transport enterprises» [4]. These studies mainly provide general theories and methods for the optimal development of production and technical facilities. Lectures and seminars on this topic were also read at scientific and practical conferences. Among them was a seminar on the topic «The experience of organizing and the prospects for the development of the production and technical base of automobile enterprises», where the issues of the prospects for the development of production and technical facilities in the studied time were considered. Textbooks were written by such authors as I. P. Kurnikov. [2] «Development of the production and technical base of road transport», Kartashov V.P. [5] «Development of the production and technical base of road transport enterprises», Mukhin E. M. [6] «Prospects for the development of the production and technical base of road transport in the Leningrad region», Napolskiy G. M. [7] «Feasibility study of the development of the production and technical base of road transport in the region», Rybin N. N. [8] «Development of the 
production and technical base of road transport enterprises». In his monograph entitled «Actual problems of innovative development of the production and technical base of the Russian industry» Safonov E. N. [9] outlined the main problems of the development of the production and technical base of the Russian industry. Research shows that much less attention is paid to the production and technical base, which ensures the efficiency and serviceability of equipment.

In the work of Lysanov D. M. [10] «Development of a methodology for assessing the efficiency of the production and technical base of car service enterprises», a mathematical model for the rational placement of car service enterprises is developed; methodology for selecting technological equipment that is an active part of the production base; simulation model of the functioning of the car maintenance and repair system at car service enterprises.

Bugaev K. V. [11] in his work «Determination of the parameters of the production and technical base of motor transport enterprises taking into account climatic conditions» proposed a simulation model of the influence of external factors and internal parameters on the costs associated with the construction, maintenance and heating of buildings for maintenance and repair of vehicles.

In the studies of Efimenko D. B. [12] «Substantiation of directions for restructuring the production and technical base of urban passenger transport» the purpose of the work is to increase the stability of the functioning of the production and technical base, in terms of bus transportation, by restructuring the production and technical base of the complex of enterprises (at the regional level), ensuring the maintenance rolling stock (city buses) in good technical condition. He proposes to develop a mathematical model to determine the regularities of the influence of the structure of the city bus fleet on the need for elements of the production and technical base and to develop theoretical principles for the formation and assessment of the effectiveness of directions for the development of the structure of the production and technical base, taking into account the forecast options for the development of passenger transport at the regional level.

Research on improving the efficiency of the functioning of production and technical facilities was reflected in the dissertation of Yu. B. Taganov [13] «Improving the structure of the production and technical base of motor transport enterprises, taking into account the age composition of the car fleet». In this work, the author has developed the most significant factors that form the structure of the production and technical base; solved the scientific and practical task of improving the structure of the production and technical base, taking into account the age composition of the vehicle fleet. A mathematical model has been also developed that describes the process of functioning of the production and technical base, regularities of the influence of the structural elements of the production and technical base on the efficiency of its functioning have been obtained.

The purpose of the study is to develop mathematical models for the formation of a rational fleet of machines for performing reclamation works and security in repair and technical impacts, taking into account the reliability indicators of basic and aggregated machines.

Russian machine-building plants do not have design documentation for modern reclamation machines, and if some of them still have it, then these are samples of 30-40 years ago - outdated and uncompetitive. To resume the production of machines, it will take more than one year, since design development, production and testing of prototypes, the creation of equipment and the development of production are necessary [11-13].

For its implementation, it will be necessary to create and equip reclamation organizations with a park of special high-performance and efficient equipment.

Based on the analysis, it was found that about $20 \%$ of the fleet of machines does not participate in the work due to technical failures, of which planned downtime associated 
with the need for maintenance or routine repairs make up a small part of the total annual working time fund, approximately $2-3 \%$, the main share is emergency failures of $40 \%$, which must be taken into account when forming the fleet of machines and when creating a system for their maintenance (Fig. 1).

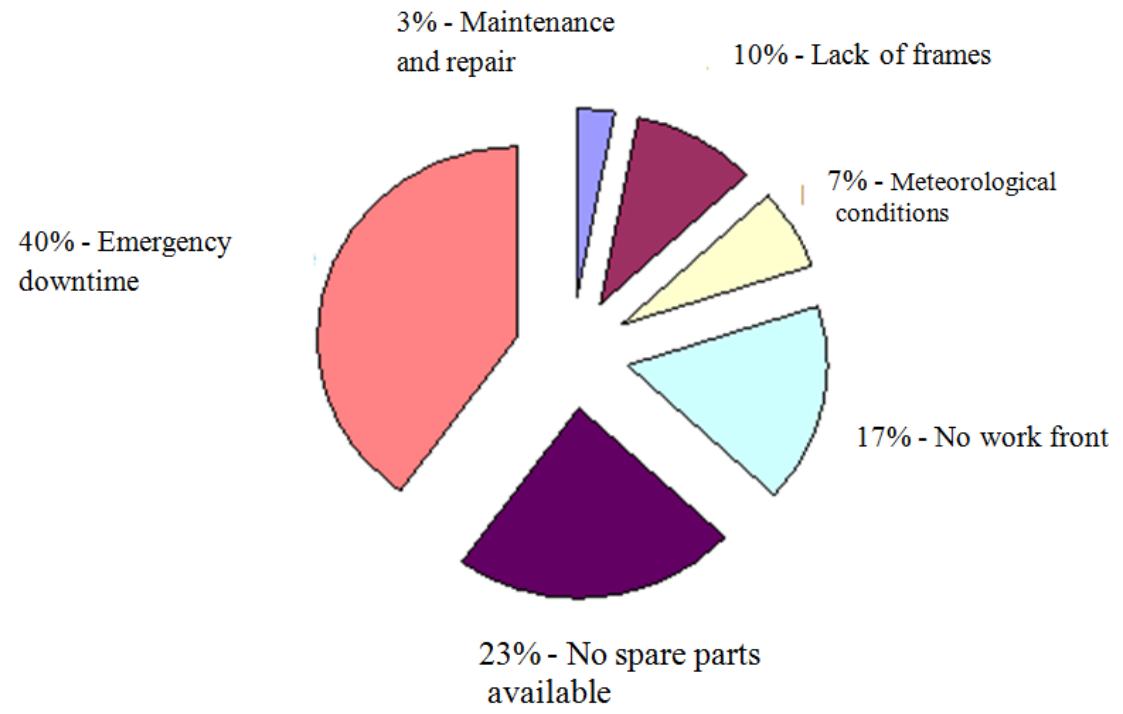

Fig. 1. Reasons for downtime of units of technological complexes.

When processing experimental data using mathematical statistics, the distribution laws were determined, as well as the average values of the random variables under study (the operating time between technical failures and the recovery time of the machines).

\section{Materials and methods}

The paper used research methods, including: analysis of literature sources devoted to the selection and determination of the required number of machines for reclamation works; analysis and systematization of existing and future technological processes and machine systems as objects of research in the formation of a fleet of machines, taking into account the characteristics of reclamation enterprises. The paper uses the methods of operations research, mathematical statistics and mathematical modeling on a computer.

We have proposed to introduce an element into the objective function that would take into account the possible costs of unplanned downtime [14-16]. The algorithm for solving the problem of increasing the operational efficiency of the fleet of machines of land reclamation organizations has the following scheme.

1. Determination of the initial (original) range of standard machine sizes. The range of machines is selected according to the type of work with reference to standard sizes and soil conditions, as well as on the basis of feasibility studies. In case of technological necessity, the product range should also include equipment, the performance of work without which is impossible, even if its use is unprofitable for economic reasons.

2. Determination of the annual operational productivity of the machines.

The annual operational productivity of machines is determined according to generally accepted methods based on Unified Norms and Prices for earthworks.

3. Determination of the cost of machine-hour of operation of the $i$-th machine.

Produced on the basis of the methodology for determining the cost of machine-hour for land reclamation and construction machines. 
4. Determination of the initial (original) amount of work performed by each $i$-th standard size of machines.

The volume of work by type (i.e. the specific volume of work of a particular type) in physical terms is taken in proportion to the volume of work performed by the organization in accordance with the reporting data of the organization on the total volume of excavation performed by it in the reporting period.

Excavation works by type are distributed on the basis of projects for the production of work in accordance with their technological sequence. To facilitate the further formalization of the task and bring the system of indicators to a certain series, we believe that all the work specified in the projects for the production of work is carried out in accordance with the data of uniform norms and prices for construction, installation and repair and construction work for the production of earthworks.

5. Determination of the initial volume of work performed on the $j$-th objects by the $i$-th standard sizes of machines.

The determination of the initial scope of work was carried out on the basis of work production projects at the facilities that the organization performs.

6. Determination of the optimal number of the $i$-th machines performing the $j$-th work, and the total minimum reduced costs for performing the given volumes of the $j$-th work (the first stage of determining the optimal composition).

7. Determination of the optimal composition of the technological complex of machines, taking into account the equipment available in the organization.

8. Determination and adjustment of operating costs for the maintenance of a technological complex of machines that is different from the optimal one.

9. Determination of costs from downtime of equipment in an inoperative state: costs of transportation to the place of repair, costs of repairs and costs of commissioning, costs of downtime while waiting for repairs, adjustment of the composition of machines.

10. Determination of the reduced costs for the operation of a complex of technological machines.

The flow of requirements for maintenance and repair is formed as a result of the impact of various random factors on the objects of operation. Machine failure is a random phenomenon, but the reasons for the occurrence of failures are associated with certain physical and mechanical processes occurring in the materials and structures of elements and systems during their operation [17-20].

The schematic diagram of the system of operational support, trouble-free operation of the units of technological complexes, is shown in Fig. 2.

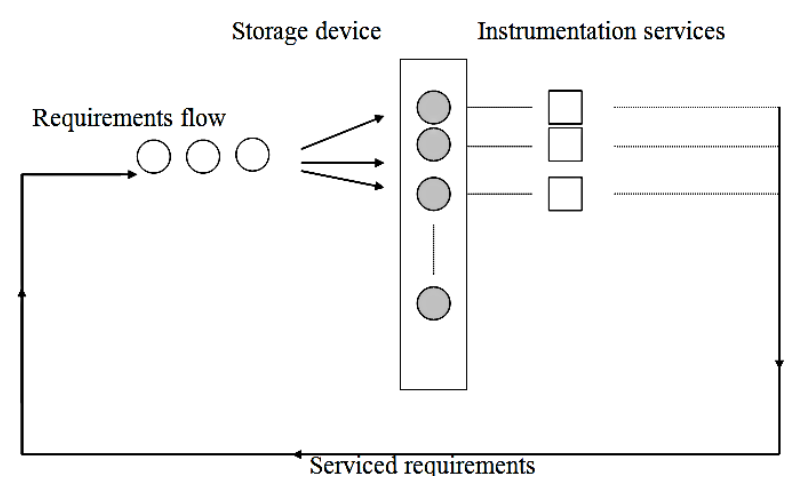

Fig. 2. Schematic diagram, systems of operational support, trouble-free operation of units of technological complex. 
To study the optimal security of repair and technical impacts, we took a set of machines for radical improvement that do not need to drain the land. The complex includes the following units: KF-2.8 brush cutter based on the DT-75M tractor; MP-15 loader collector based on the DT-75M tractor; BDM-2.5 reclamation harrow based on the DT-75M tractor; BDT-3.0 heavy disc harrow based on the DT-75M tractor; PV-1.5 wood residue picker based on the DT-75M tractor; VP-8 planner based on the DT-75M tractor; ice rink waterfilling ZKVB-1.5 A based on the DT-75M tractor; -the APP-2.8 seeder based on the DT$75 \mathrm{M}$ tractor.

These machines are typical, both for the performance of works on watering peatlands, and for cultural works, they have found the greatest application in the performance of land reclamation works.

\section{Results}

The mathematical model, the tasks of increasing the efficiency of the operation of machines of the technological complex, are presented as follows.

There are $n$ different types of work on which $\mathrm{m}$ standard sizes of earth-moving machines can be used. The machines must ensure the fulfillment of the required volumes of the $j$-th types of work in the $k$-th periods.

It is necessary to determine the number of earth-moving machines of the $i$-th standard size for the $j$-th type of work in the $k$-th period.

The optimization criterion is the minimum of the reduced costs for the entire complex of works:

The objective function:

$$
F=\sum_{i=1}^{m} \sum_{j=1}^{n} C_{\mathrm{k}=1}^{\mathrm{n}} \mathrm{C}_{\mathrm{j} k \mathrm{k}} \times \mathrm{x}_{\mathrm{ijk}} \times \mathrm{t}_{\mathrm{k}}+\sum_{\mathrm{i}=1}^{\mathrm{m}} \mathrm{A}_{\mathrm{i}} \times \bigsqcup_{\mathrm{mi}} \times \mathrm{x}_{\mathrm{i}}+\sum_{\mathrm{i}=1}^{\mathrm{n}}\left(\mathrm{C}_{\mathrm{P}}\right) \times \mathrm{x}_{\mathrm{i}} \rightarrow \mathrm{min},
$$

where $C_{i j k}$ - current operating costs of the $i$-th standard size of machines at the $j$-th job in the $k$-th period;

Operating costs include the following costs:

- the cost of transporting machines from object to object;

- the cost of replacing and repairing replaceable equipment, tool accessories;

- fuel costs;

- costs for lubricants;

- costs for wages of drivers and driver assistants;

- the cost of storing the machine;

- the cost of scheduled maintenance and repair.

$x_{i j k}$ is the number of machines of the $i$-th standard size at the $j$-th job in the $k$-th period;

$i, j, k$ - machine size indices, types of work and period, respectively $\left(i_{e}|I|, j_{e}|I|, K_{e}|K|\right)$;

$t_{n}$ is the duration of the $k$-th period;

$A_{i}$ - depreciation rate for the $i$-th car;

$\bigsqcup_{m i}-$ the price of the $i$-th car;

$C_{P}-$ costs of unscheduled repairs.

$$
C_{p}=C_{B P}+\Pi_{\Pi P,}
$$

where $\mathrm{C}_{\mathrm{BP}}$ - the cost of unscheduled repairs, rubles;

$\Pi_{\Pi \mathrm{P}}-$ losses from machine downtime due to technical reasons (rubles / hour);

$$
C_{B P}=C_{P P}+C_{34}
$$


where $C_{P P}$ - the cost of wages of repair workers, rubles; $C_{34}$ - the cost of spare parts and repair materials, rubles.

$$
\mathrm{C}_{\mathrm{PP}}=\sum_{i=1}^{n} C_{\mathrm{YP}} \cdot \mathrm{K}_{\Pi} \cdot \mathrm{T}_{\mathrm{T}}
$$

where $C_{\Psi P}$ - hourly tariff rate of the weighted average category of repair workers, rubles / hour;

$\mathrm{K}_{\Pi}-$ coefficient that takes into account the premium;

$\mathrm{T}_{\mathrm{T}}$ - the average time of the repair, hours.

$$
\mathrm{C}_{3 \mathrm{Y}}=\sum_{i=1}^{n} \mathrm{C}_{\mathrm{PP}} \cdot K_{\mathrm{PM}} \text {, }
$$

where $K_{P M}$ is the transition coefficient from the wages of repair workers to the cost of spare parts and repair materials.

Under the following restrictions:

1. Mandatory performance of all works

$$
\sum_{i=1}^{m} \Pi_{i j k} \cdot x_{i j k} \geq V_{j k}\left(j_{e}|I|, k_{e}|K|\right),
$$

where $\Pi_{i j k}$ is the operational performance of the $i$-th machine at the $j$-th job in the $k$-th period;

$V_{j k}$ - the amount of work of the $j$-th type in the $k$-th period.

2. Non-negativity of variables

$$
\mathrm{x}_{\mathrm{ijk}} \geq 0 \quad\left(i_{e}|I|, j_{e}|I|, k_{e}|K|\right) .
$$

The number of machines in the periods used is not more than in the optimal fleet:

$$
\sum_{i=1}^{m} x_{i j k} \leq x_{j k}\left(k_{e}|K|\right)
$$

3. Mandatory priority use of equipment available in the park:

$$
\mathrm{x}_{0}-\mathrm{x}_{\mathrm{i}}^{\mathrm{N}} \geq \mathrm{x}_{\mathrm{i}}^{\mathrm{P}} \text {. }
$$

where $\mathrm{x}_{i}^{\mathrm{N}}$ - the number of $i$-th machines in the fleet:

$\mathrm{x}_{i}^{\mathrm{P}}$ - the number of purchased $i$-x machines.

In addition, it is necessary to introduce into the task condition a restriction on the mandatory presence of a certain type of machines in the fleet, caused by technological reasons, a restriction on the number of machine operators working in the Mobile Mechanical Division, etc. It should be noted that when determining the «optimal» fleet, not promising equipment was excluded from the number of recommended machines (even formally having the best indicators of the reduced costs for individual works).

A mathematical model of the security of repair and technical impacts, taking into account the reliability indicators of basic and aggregated machines.

The process of accumulation of technical failures, as a rule, is described on the basis of statistical data on the uptime of the unit [21-23]. In this case, when processing of experimental data by methods of mathematical statistics, it was determined that the law of distribution of operating time between technical failures is consistent with the exponential law of distribution with a probability density:

$$
f(t)=\lambda \exp (-\lambda t)
$$

where $\lambda$ - the intensity of sudden failures. 
Machines of the technological complex (the source of service requests), during operation, create a stream of random technical failures with an intensity of $\lambda$, which is defined in general form from the expression:

$$
\lambda=\frac{1}{\mathrm{~T}_{\mathrm{cp}}}
$$

where $\mathrm{T}_{\mathrm{cp}}$ - average operating time between technical failures, $\mathrm{h}$.

The elimination of the consequences of technical failures of machines during operation is provided by repair and maintenance posts (maintenance devices). At the same time, each of the devices can serve only one request at a time with an intensity of $\mu$, determined from the expression:

$$
\mu=\frac{1}{t_{3}+t_{n}+\left(\frac{L_{p}}{V_{p}}\right)+t_{y}},
$$

where $t_{3}$ - the time from the occurrence of the request to the receipt of the request to the repair and maintenance company, $\mathrm{h}$;

$t_{n}$ - time of preparation of the team for departure, h.;

$L_{p}$ - moving distance, $\mathrm{km}$;

$V_{p}$ - the average speed of movement of the repair team, $\mathrm{km} / \mathrm{h}$. ;

$t_{y}$-average recovery time of the working condition of the machine (tractor, tool), $\mathrm{h}$.

$$
\mu_{\mathrm{a}}=\frac{\mu_{\mathrm{tr}} \lambda_{\mathrm{tr}}+\mu_{\mathrm{or}} \lambda_{\text {or }}}{\lambda_{\mathrm{a}}},
$$

where $\mu_{t r}, \mu_{o r}$ - failure rate for basic and aggregated machines;

$\lambda_{t r}, \lambda_{\text {or }}, \lambda_{a^{-}}$the intensity of technical failures of basic, aggregated machines and aggregates.

The analysis of the flows of technical failures of machines for the considered cultural complexes showed that they have the properties of the simplest (Poisson) flow. The operation of superposition of flows can be defined by Poisson flows, it consists in the fact that the incoming $\mathrm{m}$ independent Poisson flows of intensity $\lambda_{\kappa}, k=1, m$ are combined into a single flow.

In queuing theory, it is proved that the following theorem holds: the superposition of $\mathrm{k}$ independent Poisson flows of intensities $\lambda_{k}, k=1, m$ is again a Poisson flow of intensity $\lambda=\sum_{\mathrm{k}=1}^{\mathrm{m}} \lambda_{\mathrm{K}}$.

In the case under consideration, there are two Poisson flows with intensities:

$\lambda_{t r}$ - the failure rate of the base machines;

$\lambda_{\text {or }}$ - the failure rate of the aggregated machines.

These flows are independent and, therefore, from the above theorem, we can introduce the failure rate of the aggregate $\lambda_{a}$, which in this case will be equal to $\lambda_{\mathrm{a}}=\lambda_{\mathrm{tr}}+\lambda_{\text {or }}$. This means that when modeling the operation of the unit, you can use models of a queuing system (QS) with a failure rate of $\lambda_{a}$.

From the point of view of the principles of the system approach, the interaction of elements (machine, repair and maintenance post, service queue (storage device)) it can be represented as a system of operational maintenance of the trouble-free operation of the units of technological complexes [24, 25].

Taking into account the above, the model of the system of operational maintenance of the trouble-free operation of the units of cultural complexes was presented as a queuing system, corresponding, according to the classification of the Kendell-QS M/M/1 (M/M/m), 
which has the following characteristic features: the probabilistic process of functioning of this system corresponds to a special case of the Markov process - the process of reproduction and death; this system belongs to the closed QS without losses with the discipline of servicing applications in the order of receipt; it is multi-channel with a limited number of service stations; the system performance is controlled by varying the number of service devices and sources of service requests [26].

As the main criterion for the efficiency of the use of the complex of machines, the criterion was adopted - the minimum cost of operating the units, taking into account the losses from the downtime of the basic and aggregated machines for technical reasons, per one hectare of cultural works.

The objective function has the form:

$$
\mathrm{Y}_{(\mathrm{a})}=\frac{\mathrm{C}_{1} \mathrm{M}_{0(\mathrm{a})}+\mathrm{C}_{2}\left(\mathrm{M}-\mathrm{M}_{\mathrm{o}(\mathrm{a})}\right)+\mathrm{C}_{3} \mathrm{~s}}{\mathrm{MW}} \rightarrow \min ,
$$

where $\mathrm{Y}(\mathrm{a})$ is the minimum cost of operating the units, rub / ha.; $\mathrm{C}_{1}$ is the loss from downtime of the unit, rub / $h ; C_{2}$ is the direct cost of operating one unit, rub./h.; $C_{3}$-the cost of maintaining the repair and maintenance posts, rub./h.; Mo(a) - the average number of non - operational units, pcs.; $(\mathrm{M}$ - Mo(a)) - the average number of operational units, pcs.; $\mathrm{S}$ - the number of repair and maintenance posts in the system, pcs.; Kp(a) - the idle time of units; W0-the average hourly operating capacity of one technological complex, ha/h, M-the total number of units. The values of $\mathrm{Mo}(\mathrm{a}),(\mathrm{Mo}(\mathrm{a}))$, and $\mathrm{Cp}(\mathrm{a})$ are random variables and are determined using queuing theory methods.

As a result of the calculations carried out for the complex of machines for watering peatlands, the hypothesis about the normal distribution of the values of the machine's operating time for failure and the time of elimination of failures was proved. The data obtained are presented in table 1.

Table 1. Calculated data obtained.

\begin{tabular}{|c|c|c|c|c|c|c|c|c|}
\hline \multirow[t]{2}{*}{ Machine } & \multicolumn{4}{|c|}{ Operating time } & \multicolumn{4}{|c|}{$\begin{array}{c}\text { Time to eliminate } \\
\text { unscheduled failures }\end{array}$} \\
\hline & 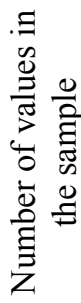 & 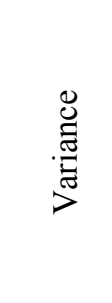 & 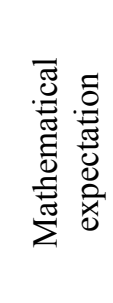 & 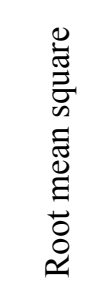 & 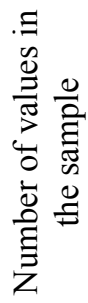 & 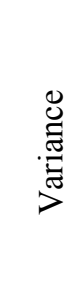 & 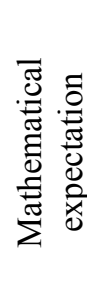 & 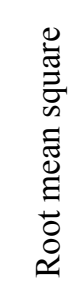 \\
\hline Bulldozer DZ-170 & 28 & 337.57 & 111.8 & 18.37 & 28 & 3.33 & 2.51 & 1.82 \\
\hline Excavator ET-26 & 28 & 377.7 & 116.71 & 19.43 & 28 & 5.11 & 4.71 & 2.26 \\
\hline $\begin{array}{l}\text { Motor Grader DZ- } \\
122\end{array}$ & 28 & 467.83 & 123.53 & 21.62 & 28 & 5.06 & 4.73 & 2.24 \\
\hline
\end{tabular}

It is found that the average time to failure for bulldozer DZ-170 is equal to $111.8 \mathrm{mash} \cdot \mathrm{h}$, excavator ET-26 is equal to $116.71 \mathrm{mash} \cdot \mathrm{h}$, for autograders-122 is equal to 123.53 mash.h., and the average time of recovery, respectively, is equal to 2.51 people, of 4.71 persons hrs, 4.73 people $\cdot h$.

Comparison of operating costs, taking into account the losses from downtime due to technical reasons in the developed and existing methods is presented in Fig. 3. Fleet adjustment under specific conditions of land reclamation. 


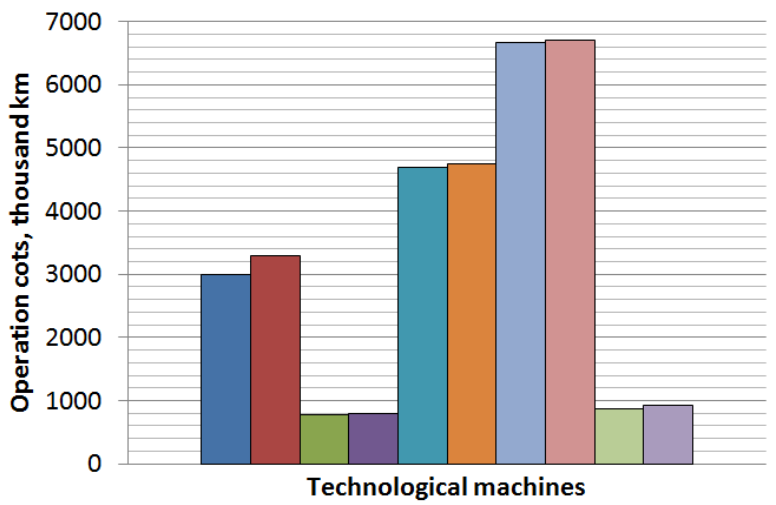
ET-26 (developed methodology)
ET-26 (existing methodology)
KC 55713 (developed methodology)
KC 55713 (existing methodology)
DZ-170 (developed methodology)
DZ-170 (existing methodology)
KAMAZ-6520 (developed
methodology)
KAMAZ-6520 (existing methodology)

Fig. 3. Comparison of operating costs calculated using existing and developed methods.

Statistical analysis of the bulldozer park allowed us to draw the following conclusion. The annual operating time of these machines has a clear tendency to decrease with increasing «age» (Fig. 4).

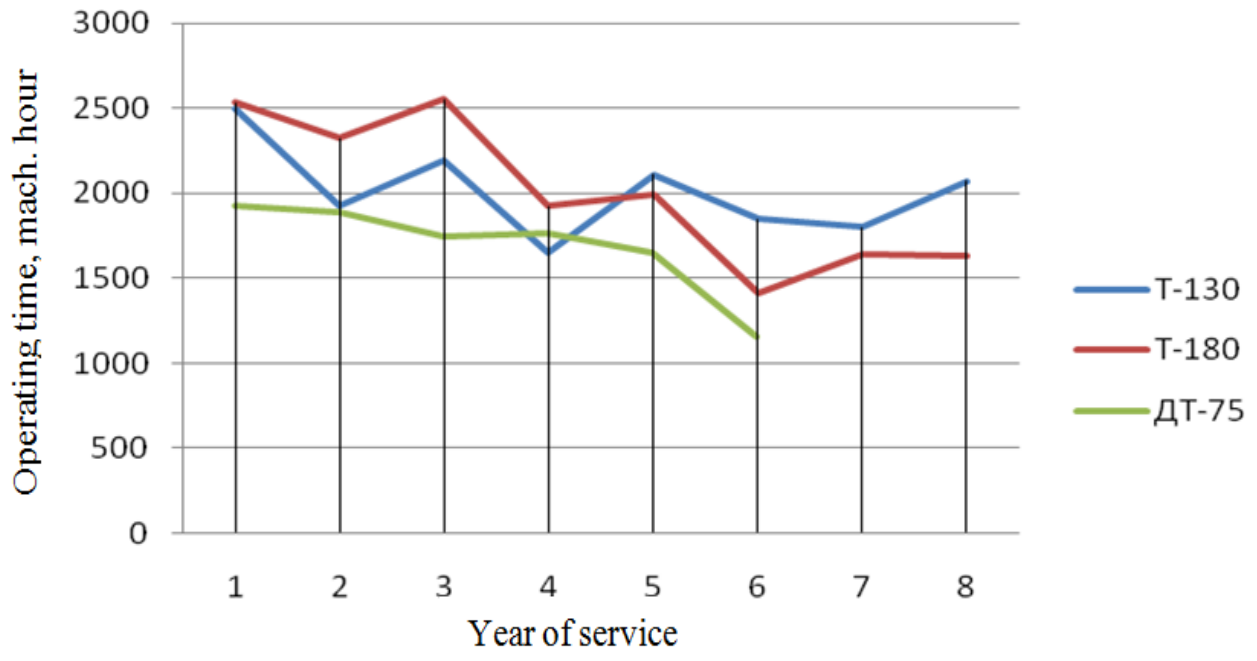

Fig. 4. Annual operating time of machines.

The analysis of the work of the units of the cultural complex showed that the reliability indicators of the basic and aggregated machines differ sharply from each other. The average time to failure of aggregated machines is four times less than that of basic machines.

Further, for the aggregates of the cultural complex, we determined the distribution laws and the average values of the random variables under study (the operating time between technical failures, as well as the recovery time of the basic and aggregated machines). Graphs of the probability distribution density are shown in Figs. 5a and 5b. 

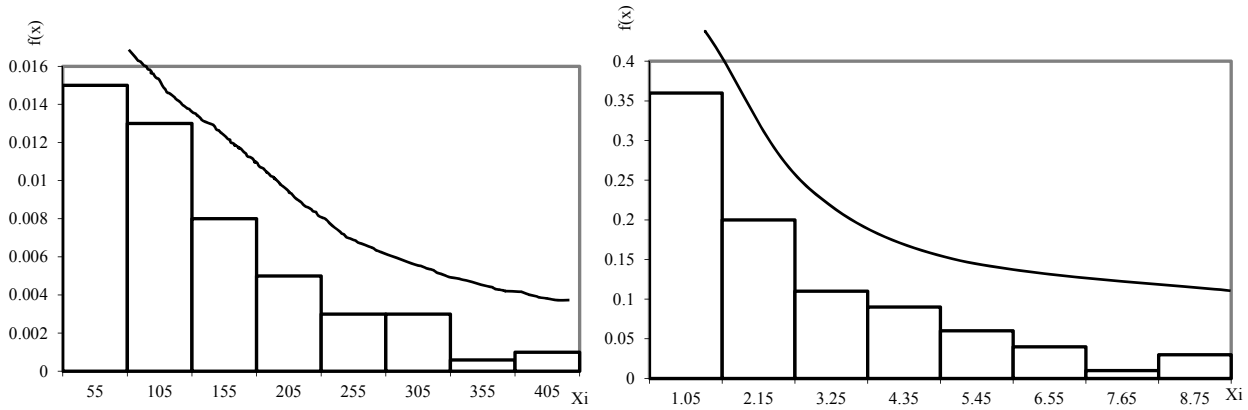

a)
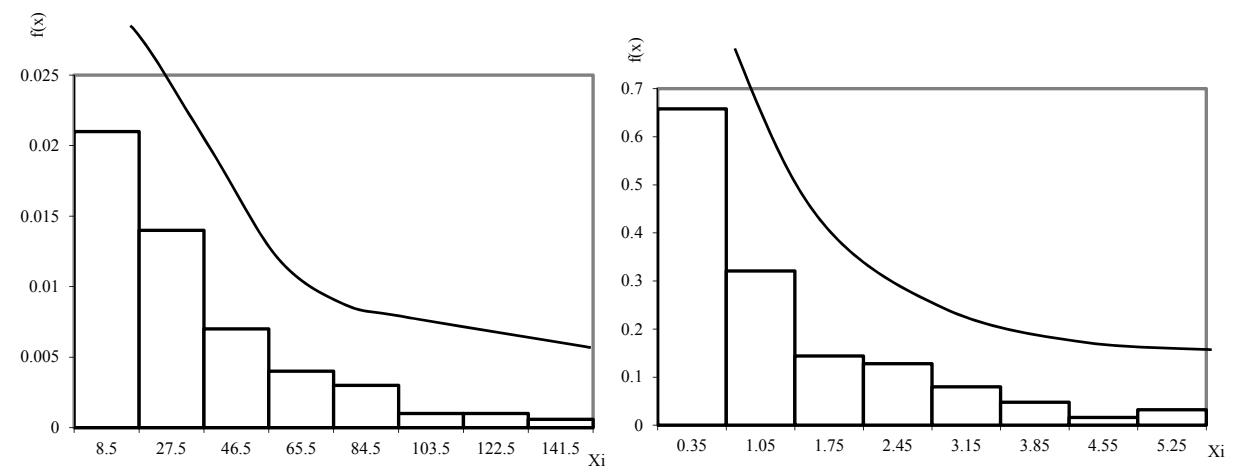

b)

Fig. 5. The density of the distribution of the probability of operating time between technical failures and the time to eliminate the consequences of technical failures: a) a group of basic machines (tractor); b) aggregated machines (tools), aggregates.

It is established that the average time to failure for basic machines is 139.3 machine hours, for aggregated machines is 35 machine hours, and the average failure recovery time for basic machines is 2.22 man-hours, for aggregated machines is 1.27 man-hours.

Thus, analyzing the reliability indicators of the units of cultural complexes, it should be noted that when operating them, it is necessary to take into account the reliability indicators not only of the basic machine, as it was before, but also the reliability indicators of the aggregated machines, since the tools have low reliability indicators and significantly reduce the technical and operational indicators of the unit as a whole.

\section{Discussion}

Thus, a technique has been developed for forming the optimal composition of machines for performing reclamation work, which takes into account the costs and losses from unplanned failures of machines, including machines of technological complexes, consisting of both domestic and foreign samples. Timely elimination of unplanned failures will reduce losses from downtime, increase the efficiency of their operation and the profitability of the enterprise as a whole [27].

Indicators of the reliability of machines for performing reclamation work (the operating time of the machine for failure and the time, i.e. (duration) of eliminating the consequences of failures) are subject to the normal distribution law. When completing the fleet of machines and predicting its performance, it is necessary to take into account the reliability indicators of not only basic, but also aggregated machines [28, 29]. So about $70 \%$ of 
failures of complexes for performing cultural works are caused by the failure of the aggregated machine.

The functioning of the fleet of domestic and foreign machines with different degrees of reliability requires the study of the issues of rational selection and optimization of staffing [30]. This requires special techniques that would take into account the costs of unplanned downtime of equipment and ensure their operability. When building a system for maintaining machines in working condition and optimizing the technical equipment of the production and technical base of reclamation organizations, it is necessary to take into account the features of the modern period, including the formation of a dealer service system.

\section{References}

1. A. F. Zakuraev, I. P. Kupnikov, Improvement of the forms of development of the production and technical base of the transport management enterprises. Dissertation for the degree of candidate of technical sciences, Moscow: Kiev Automobile and Road Institute named after V.I. 60 lithium of the Great October Socialist Revolution, 173 (1984)

2. I. P. Kurnikov, The main directions of development and effective use of the production and technical base of road transport. Dissertation for the degree of Doctor of Technical Sciences, (Kiev Automobile and Road Institute named after V.I. 60 lithium of the Great October Socialist Revolution, Moscow, 332, 1981)

3. E. R. Umarov, Modeling the development of the production and technical base of road transport. Dissertation for the degree of candidate of economic sciences (Tashkent, Moscow 169, 1988)

4. A. V. Kamoltseva, The system for assessing the state of the production and technical base of motor transport enterprises. Dissertation for the degree of candidate of technical sciences (Krasnoyarsk State Technical University, Moscow, 136, 1997)

5. V. P. Kartashov, Development of the production and technical base of motor transport enterprises. Tutorial (Transport, Moscow, 3-150, 1991)

6. E. M. Mukhin, V. Yu. Dzhangulov, V. S. Martynov, Prospects for the development of the production and technical base of automobile transport in the Leningrad region. Tutorial (LDNTP, Leningrad, 3-20, 1991)

7. G. M. Napolsky, A. V. Pugin, Feasibility study of the development of the production and technical base of motor transport in the region. Tutorial (MADI, Moscow, 3-65, 1990)

8. N. N. Rybin, Development of the production and technical base of road transport enterprises. Tutoria (Kurgan Machine-Building Institute, 3-145, 1994)

9. E. N. Safonov, G. A. Palamarenko, Features of the formulation of the goals of the innovative strategy of the enterprise in modern economic conditions, in Collection of materials of the interregional scientific-practical conference. Part 2. Problems of improving enterprise management in modern conditions. Penza, 92 (2000)

10. D. M. Lysanov, Development of a methodology for assessing the efficiency of the production and technical base of car service enterprises. Dissertation for the degree of candidate of technical sciences (Kama State Polytechnic Institute, Moscow, 151, 2008)

11. K. V. Bugaev, Determination of the parameters of the production and technical base of motor transport enterprises, taking into account climatic conditions (Dissertation for the degree of candidate of technical sciences, Tyumen State Oil and Gas University, Moscow, 168, 2006) 
12. D. B. Efimenko, Substantiation of directions for restructuring the production and technical base of urban passenger transport. Dissertation for the degree of candidate of technical sciences (MADI, Moscow, 209, 2002)

13. Yu. B. Taganov, Improving the structure of the production and technical base of road transport enterprises, taking into account the age composition of the vehicle fleet. Dissertation for the degree of candidate of technical sciences (Kiev, Moscow, 143, 1993)

14. T. R. Gabdullin, New technologies of road construction in Russia, Materials of the international scientific and practical conference «Innovative materials, technologies and equipment for the construction of modern transport structures», publishing House of BSTU named after V.G. Shukhov, Belgorod, 109-113 (2013)

15. E. A. Vdovin, V. F. Stroganov, Properties of cement-bound mixes depending on technological factors, Magazine of Civil Engineering, 93(1), 147-155 (2020) DOI: 10.18720/MCE.93.12

16. R. L Sakhapov, R. V. Nikolaeva, M. H. Gatiyatullin, M. M. Makhmutov, Asphalt granulate coating for roadsides, MATEC Web of Conferences 245 International Scientific Conference on Energy, Environmental and Construction Engineering (EECE2018), 02003 (2018), DOI: 10.1051/matecconf/201824503014

17. Viktor Myronenko, Valerii Samsonkin, Serhyi Rudkovskyi, American Journal of Engineering Research (AJER), 5, 238-244 (2017), URL: www.ajer.org/ (last accessed: 25.03.2021)

18. Sanz Penabad, Laksmi \& Ramos, Pedro \& Iznaga Benítez, Arsenio, Freight vehicle condition monitoring through the availability, Dyna (Medellin, Colombia), 85 (2018) DOI: 10.15446/dyna.v85n205.68443

19. Afshar-Nadjafi, Behrouz \& Afshar-Nadjafi, Alireza. A constructive heuristic for timedependent multi-depot vehicle routing problem with time-windows and heterogeneous fleet, Journal of King Saud University - Engineering Sciences, 29(1). 29-34. (2017) DOI: 10.1016/j.jksues.2014.04.007

20. Gahm, Christian \& Brabänder, Christian \& Tuma, Axel, Vehicle routing with private fleet, multiple common carriers offering volume discounts, and rental options, Transportation Research Part E Logistics and Transportation Review, 97, 192-216 (2016) DOI: $10.1016 / j$.tre.2016.10.010

21. Kallrath, Josef \& Klosterhalfen, Steffen \& Walter, M. \& Fischer, G. \& Blackburn, R., Payload-based fleet optimization for rail cars in the chemical industry. European Journal of Operational Research, 259, 113-129 (2016) DOI: 10.1016/j.ejor.2016.09.062

22. S. T. Klosterhalfen, J. Kallrath, G. I. Fischer, Rail car fleet design: Optimization of structure and size, International Journal of Production Economics, 157, 112-119 (2014) DOI: $10.1017 / \mathrm{S} 0890060419000428$

23. A. N. Melnikova, I. I. Lyubimova, K. I. Manayev, Improvement of the Vehicles Fleet Structure of a Specialized Motor Transport Enterprise, Procedia Engineering, 150, 1200-1208 (2016) DOI: 10.1016/j.proeng.2016.07.236

24. N. Arslan Ayşe, Dimitri J. Papageorgiou, Bulk ship fleet renewal and deployment under uncertainty: A multi-stage stochastic programming approach, Transportation Research, Part E, 97, 69-96 (2017) DOI: 10.1016/j.tre .2016.10. 009

25. Shi Ning, Song Haiqing, Powell Warren, The dynamic fleet management problem with uncertain demand and customer chosen service level, International Journal of Production Economics, 148, 110-121 (2014) DOI: 10.1016/j.ijpe.2013.09.010

26. Afenyo Mawuli, Panahi Roozbeh, Ng Adolf, Lau Yui-Yip, Reflecting on forty years contextual evolution of arctic port research: The past and now, Transportation Research Part A, Policy and Practice, 144, 189-203 (2021), DOI: 10.1016/j.tra.2020.12.001 
27. R. L. Sakhapov, R. V. Nikolaeva, M. H. Gatiyatullin, M. M. Makhmutov, Modeling of regional transport and logistics systems, Journal of Physics: Conference Series, 1141, 012133 (2018) DOI: 10.1088/1742-6596/1141/1/012133

28. V. Sultanov, M. Makhmutov, Mathematical principles of modeling processes of heat and mass exchange in multiphase media, Journal of Physics: Conference Series, 1588, 012048 (2020) DOI: 10.1088/1742-6596/1588/1/012048

29. R. Mukhametshina, Metal plating based on copper (II) complex compounds with hydroxyethylidene diphosphonic acid, IOP Conference Series: Materials Science and Engineering, 786, 012057 (2020) DOI: 10.1088/1757-899X/786/1/012057

30. Farit Khaliullin, Aleksandr Matyashin, Minsur Zemdikhanov, Aleksey Martyushev, Nikolay Davydov, Motorless pilot studies of crankshaft dampers of combustion engines, IOP Conf. Series: Earth and Environmental Science, 699, 012041 (2021) DOI: $10.1088 / 1755-1315 / 699 / 1 / 012041$ 